\title{
¿Una puerta cerrada? \\ Sobre la educación y la corrupción pedagógica de la juventud
}

\author{
FERNANDO BÁRCENA \\ Universidad Complutense de \\ Madrid, Madri, Espanha
}

\section{RESUMEN}

La educación supone una salida: salida de la minoría hacia la mayoría de edad; una salida al exterior. Sin embargo, la reducción de la experiencia de la formación a la enseñanza erosiona, en sus fundamentos y en su sentido, la magnitud y la importancia de esta salida. Bajo las condiciones de nuestras sociedades actuales, la educación supone una salida, no al mundo, sino a esa pequeña parte del mundo que es el centro de trabajo, la oficina o la fábrica. Esta salida no es una experiencia plena, y además está gobernada, administrada, diseñada y planificada por una pedagogía posteducativa cuya impostura pedagógica explora críticamente este texto.

\section{PALABRAS CLAVE}

impostura pedagógica; pedagogía posteducativa; corrupción pedagógica; experiencia educativa. 


\title{
A CLOSED DOOR? ON EDUCATION AND THE PEDAGOGICAL CORRUPTION OF THE YOUNG
}

\begin{abstract}
Education is an outdoor exit: an exit from minority to majority, an exit to the outside world. However, reducing the formative experience of education erodes the magnitude and importance of this outdoor exit, in its foundations and meanings. Under the conditions of contemporary society, education presupposes an exit not to the world, but to that little part of the world which is the workplace, be it an office or a factory. Besides not being a full experience, this exit is governed, managed, designed and planned by a post-educational pedagogy, whose pedagogical imposture this text critically explores.

KEYWORDS

pedagogical imposture; post-educational pedagogy; pedagogical corruption; educational experience.
\end{abstract}

\section{UMA PORTA FECHADA? A EDUCAÇÃO E A CORRUPÇÃO PEDAGÓGICA DA JUVENTUDE}

\section{RESUMO}

A educação é uma saída: a saída da menoridade para a maioridade; uma saída para o mundo exterior. No entanto, reduzir a experiência de formação do ensino deteriora a magnitude e a importância dessa saída, em seus fundamentos e sentidos. Sob as condições de nossa sociedade atual, a educação faz supor uma saída não para o mundo, mas para aquela pequena parte do mundo que é o local de trabalho, seja no escritório ou na fábrica. Essa saída não é uma experiência plena e, além disso, está governada, administrada, desenhada e planejada por uma pedagogia pós-educativa, cuja impostura pedagógica este texto explora criticamente.

\section{PALAVRAS-CHAVE}

impostura pedagógica; pedagogia pós-educativa; corrupção pedagógica; experiência educacional. 


\section{INTRODUCCIÓN}

La obra de teatro de Jean-Paul Sartre Huis clos (A puerta cerrada), del año 1944, se hizo famosa, sobre todo, por aquella famosa frase final: "El infierno son los otros". Si recuerdan, la obra se inicia con el mayordomo que conduce a un hombre llamado Garcin hacia un cuarto, que muy pronto se identifica como el infierno. El cuarto no tiene espejos ni ventanas y sólo cuenta con una puerta, tres sillones, una estatua de bronce y un abrecartas. Finalmente, una mujer, Inés, entra a la habitación de Garcin, y posteriormente otra, Estelle. Después de que ambas ingresan, el mayordomo sale y la puerta es cerrada con llave. Todos esperan ser torturados, pero no aparece torturador alguno. En lugar de ello, los personajes descubren que están ahí para torturarse entre sí, lo que parecen estar logrando. Al principio, los tres observan acontecimientos que les conciernen, y que suceden en la Tierra, pero finalmente son abandonados con sus propios pensamientos y la compañía de los otros dos. Al final de la obra, Garcin exige salir; tras decirlo, la puerta se abre, pero ninguno decide salir, ya que se dan cuenta de que no pueden vivir los unos sin los otros.

Aunque esta obra de teatro parece explorar el concepto de la influencia de las miradas ajenas en la psique personal-la mirada del otro es aquello que desnuda, mostrando al otro la realidad del ser-, me gustaría aquí tomarla como pretexto para tratar de evocar otra idea: la imposibilidad de una salida al exterior. Esta imposibilidad no se debe a ningún obstáculo o impedimento externo - pues nada impide que al final los personajes salgan por la puerta que se ha abierto, si lo desean-, sino al hecho de que ellos ya no desean salir afuera; no pueden vivir los unos sin los otros, se han acostumbrado demasiado a la tortura que ellos mismos se infligen. Se han educado entre sí, se han habituado y una especie de pereza, mezclada con cierta clase de cobardía, les impide salir y ver qué hay en el exterior.

Quizá recuerden también la película de Luis Buñuel El ángel exterminador, del año 1962. La historia que Buñuel trata de contar tiene que ver con un grupo de burgueses de la ciudad de México que son invitados a una cena en la mansión de los Nóbile, después de asistir a la ópera. Entretanto, los sirvientes y los cocineros sienten deseos de abandonar la mansión y se marchan. Al terminar la cena, los invitados se dan cuenta de que no pueden salir de la habitación por una razón que desconocen, aunque no hay aparentemente nada que lo impida. A medida que van pasando los días, el alimento y la bebida escasean, los personajes se enferman y la basura se va acumulando. A partir de ese momento, las buenas costumbres y la cordialidad poco a poco se acaban y los burgueses comienzan a comportarse como auténticos salvajes. E1 humor y el esperpento, bajo un manto surrealista, se dan cita en esta película para narrar la degradación del comportamiento humano ante situaciones limite, incluso en la clase social en la que presuntamente las normas de cortesía son más cultivadas.

Tanto la obra de teatro de Sartre como la película de Buñuel me sirven aquí para tratar de decir otra cosa. Son mi pre-texto, pues creo que en el mundo de la educación hoy pasa algo, hasta cierto punto, parecido: en vez de hacer de la 
educación una práctica, una actividad o una experiencia que permita al individuo salir y experimentar el mundo -atravesar las innumerables puertas que quizá están todavía abiertas- parece que se está convirtiendo en un esfuerzo pedagógicamente denodado por hacer que los jóvenes (niños y adolescentes) se adentren en la escuela, en la universidad o en la fábrica y la oficina, cuando toca, y se acostumbren allí a estar con sus iguales, quizá torturándose mutuamente.

Kant decía, en su famoso texto sobre la ilustración, que la incapacidad para usar la propia razón se debía a la pereza y a la cobardía, porque es mucho más cómodo caminar bajo la tutela ajena que hacerlo (pensar y actuar por uno mismo). En este sentido, la ilustración es un combate contra la ignorancia, contra la superstición, y concibe el saber como un instrumento de emancipación de toda clase de tutores. Para que la ilustración, en este sentido, dé sus frutos, se necesita, sin embargo, una firme voluntad capaz de huir de esa clase de servidumbre que prefiere obedecer a cambio de seguridades y de cierto bienestar pasajero. Pero hoy el saber y los conocimientos no están al servicio de esa emancipación, sino del mercado. Se inscriben en la llamada sociedad del conocimiento. En el caso de la universidad, los saberes no se orientan a la formación que emancipa sino a algún tipo de financiación pública (Pardo, 2010d). Todo tiene que ver con los proyectos de investigación y con la ingente cantidad de grupos de investigación que proliferan por todo el mundo. No tener un grupo de investigación es algo así como presentarse ante el mundo con la abstracta desnudez de no ser sino un ser humano; algo desechable y superfluo: nuda vida.

Personalmente, sospecho que esa puerta de la educación, a diferencia de la del cuarto en la obra de Sartre, que finalmente se abre, permanece definitivamente cerrada. Pero tengo muchas dudas, y eso explica los interrogantes del título principal de este texto. Pero aún suponiendo que existan algunas puertas abiertas, el caso es que no parece haber muchas salidas y sí, en cambio, mucha corrupción, mucha corrosión y cierta dosis de parálisis.

Tal vez mi idea de la universidad esté pasada de moda, y acepto que se me pueda acusar de ser un individuo melancólico que reivindica un mundo ya definitivamente desaparecido. No lo sé; pero estoy aprendiendo a aceptar algunos consejos de buenos amigos y amigas, algunos de ellos muy jóvenes y sumamente inteligentes, que me han dado a pensar en lo peligroso que puede resultar esa melancolía convertida en vicio, y que a veces me da la sensación de ser un náufrago agarrado a una tabla repleta de objetos que un día tuvieron un sentido (pero solo para mí) y que en las condiciones actuales son, francamente, un estorbo: acabarán, si me empeño, por hundirme rápidamente en lo más profundo del mar abierto. Lo mejor es ir a nado a la orilla, que quizá tampoco está tan lejos.

De todos modos, hay cosas que hemos perdido que merece la pena echarlas de menos, o al menos recordarlas. O sea: que hay cosas que merecen la pena, como las vidas desaparecidas merecen ser lloradas y echadas de menos. Se trata de saber qué cosas merecen algún tipo de pena. Por lo que a mí respecta, no creo que mi melancolía, si la tengo, tenga que ver con esa actitud que se empeña en decir que nada de lo que hay en el presente merezca la pena de ser visto. $Y$ en lo que respecta a los 
estudios humanísticos, y los estudios de educación pertenecen, en mi opinión, a este campo, estoy convencido de que lo que realmente merece la pena investigar y estudiar con seriedad es el buen ordenamiento de los planes académicos, la forma como deberían trasladarse los conocimientos a los estudiantes y los medios para ayudar a los jóvenes a ser, no solo personas más sabias, sino hombres y mujeres de cierta categoría moral. ¿Merece la pena revitalizar las antiguas aspiraciones de la paideia o de la Bildung?

Me gustaría, pues, en lo que sigue, ofrecer, a partir de esta imagen inicial que tomo de Sartre, algún tipo de reflexión acerca de lo que, en mi opinión, supone una reducción de la educación -entendida como lo que nos emancipa, lo que nos hace ser mayores de edad, o lo que nos hace salir de nuestra infancia- a la enseñanza, considerada como una actividad programada y orientada a la adquisición de una serie de competencias por parte de un aprendiz que aspira o es empujado a ser adulto accediendo al mercado de trabajo. En mi opinión, este tipo de reduccionismos imaginan poder comprender el "todo" (aquello que consiste en prepararse para salir al mundo y experimentarlo) por la explicación de una de sus partes (salir a la oficina, a la fábrica o al centro del trabajo, que, aunque forman parte del mundo, no son el mundo).

La educación supone una salida: salida de la minoría hacia la mayoría de edad; una salida al exterior. Pues bien, la restricción de la educación a la enseñanza erosiona, en sus fundamentos y en su sentido, la magnitud y la importancia de esta salida. Bajo las condiciones de nuestras sociedades actuales, y enseguida hablaré de ellas, supone un salir de casa para ir a la escuela o a la universidad, pero para quedarse el aprendiz allí encerrado. Supone una salida, no al mundo, sino a esa diminuta parte del mundo que es el centro de trabajo, la oficina o la fábrica. Ambas salidas no son experiencias plenas, y además están gobernadas, administradas, diseñadas y planificadas por una pedagogía posteducativa cuya impostura pedagógica me interesa explorar últimamente.

\section{APRENDER EN UNA SOCIEDAD DE LABORANTES}

La cuestión que voy a desarrollar se sostiene en una tesis, que tiene dos partes o dimensiones.

La primera parte de mi tesis viene a decir algo que ya destacó Hannah Arendt en La condición humana. Vivimos en una sociedad de consumidores o de "laborantes", en la cual cualquier cosa que hacemos se supone que la hacemos para "ganarnos la vida". Esta es una tesis social fuerte, y el número de personas capaces de desafiar esta creencia es cada vez menor. Cada actividad social es un medio, y solo un medio, para ganarse la vida, da lo mismo la naturaleza de la misma. De ahí que todas las actividades "serias", con independencia de sus frutos, se denominen "labor", y aquellas que no son necesarias para la vida del individuo, en este estricto sentido de la expresión, pasan de inmediato a otra clase de categoría (por ejemplo, una mera "diversión"), es decir, se clasifican como actividades "no serias". Arendt 
insistía en algo que me parece fundamental entender aquí: con la modernidad, la sociedad se constituye en la "organización pública del propio proceso de la vida" (Arendt, 1993, p. 56), y ello conduce directamente a pensar la sociedad humana como una sociedad de laborantes, de trabajadores y empleados, una sociedad centrada en figuras dedicadas a mantener la vida. Ahora bien, lo importante de este argumento está en que para obtener una sociedad de trabajadores "no es necesario que cada uno de los miembros sea trabajador [...], sino que todos sus miembros consideren lo que hacen fundamentalmente como medio para mantener su propia vida" (idem, ibidem). O dicho de otro modo: la sociedad es la forma en que la mutua dependencia en beneficio de la vida, y nada más, adquiere un significado público; "donde las actividades relacionadas con la pura supervivencia se permiten aparecer en público” (idem, p. 57). De ahí que no extrañe que actividades como la educación -tanto en relación a lo que hacen los profesores como a lo que hacen los estudiantes- deban, para mantenerse con cierta credibilidad social, situarse en el registro de actividades laborantes; más como medios para el mantenimiento de la vida como para realización de la experiencia de una vida que se va formando.

La segunda parte de mi tesis es la siguiente: no es la "facilidad" en el aprender-el hecho de que sea habitual hacerlo-lo que justifica un pensamiento sobre educación, sino la experiencia de su dificultad. Porque nadie sabe cómo aprende, en qué momento lo hace y por qué mecanismos sucede. Y no se puede anticipar: "Nunca se sabe por anticipado cómo alguien va a aprender: por qué amores se llega a ser bueno en latín, por qué encuentros se es filósofo, en qué diccionarios se aprende a pensar" (Deleuze, 1968 , p. 215). Aprender, aunque es un verbo de intención más que de logro, supone, cuando se realiza, que alguna cosa se ha aprendido bien. Aprender algo es aprender a hacerlo bien (Pardo, 2004, p. 28). Y eso supone esfuerzo, dedicación y atención. Pero aprender no es sino lo que ocurre entre un no-saber y un saber, un paso viviente de uno a otro que requiere la máxima atención. Y ese pasaje del no-saber al saber está repleto de azares e imprevistos, de casualidades e incertidumbres.

En este sentido, todo proceso educativo -nada parece más razonable-, aspira a su propia eficacia: que se trate de lograr lo que se intenta; que alguien aprenda. La cuestión es, sin embargo, que contrariamente a las doctrinas (muchas de ellas arraigadas en la pedagogía) que pretenden hacer de los conocimientos (que han de aprenderse) una especie de "caja de herramientas" sin rigor ni rigidez propias -algo, en suma, que se deja utilizar hasta convertirse en un cóctel adaptado a las necesidades de cada uno-, defenderé, siguiendo una sugerencia de un filósofo español, que todo aprender tiene que ver con una experiencia donde conocer algo supone adaptarse a la lógica y al rigor de aquello que se pretende adquirir (Pardo, 2010a, p. 355). Más que adaptarse al discente o al aprendiz, hay que adaptarse al contenido a aprender y a su dificultad. El escritor y ensayista español Sánchez Ferlosio dice en uno de sus ensayos algo interesante y bastante crítico de algunas posiciones pedagógicas que se empeñan en facilitar la lectura difícil en la enseñanza. Refiriéndose a los libros de historia, dice nuestro ensayista: 
¿Acaso no sería mejor entrada, mejor iniciación, pregunto entonces, irrumpir sin más y a cuerpo limpio en el corazón del libro y penetrar en un único capítulo, haciendo presa en la materia misma, sin arredrarse ante las dificultades y demorándose en ella hasta entenderla? (Sánchez Ferlosio, 2002, p. 48)

Tener que adaptarse a la dificultad de aquello que se quiere conocer y aprender es, en cierto sentido, tener voluntad de emanciparse y pensar por uno mismo. Esta voluntad de emancipación en el aprender-que va, por así decir, al asunto de que se trate con el maximum de la atención concentrada-, se refiere a muchos objetos del mundo. Se refiere a un mundo que siempre es un mundo público o visible, porque constantemente se nos aparece y da muestras de él a través de los signos, diversos y heterogéneos, que despliega (Deleuze, 1964).

Muchas de las cosas que voy a decir en lo que sigue hay que inscribirlas en un contexto institucional determinado y exige una reflexión sobre determinadas políticas educativas. Voy a tratar de tener presente como referencia, o "caso", la educación universitaria, y me será inevitable referirme al estado de cosas que pasan en Europa, continente de donde provengo, y en instituciones como la Facultad de Educación, donde imparto mi docencia en la disciplina de filosofía de la educación. Me resultará por eso inevitable tener que hablar de la reforma de la educación universitaria conocida, y también padecida por nosotros, como Plan Bolonia.

Los orígenes de este plan se encuentran en la Declaración de la Sorbona, del año 1998, firmada por diversos ministros de educación europeos, ${ }^{1}$ y posteriormente en la Declaración de Bolonia, de 1999, a las que siguieron otras tantas en Praga (2001), Berlín (2003), Bergen (2005), Londres (2007) y Leuven (2009).

Los redactores de la Declaración de la Sorbona tenían en mente una idea de Europa basada en la unidad monetaria y económica. Pero como la mala conciencia de la que hablaba Hegel es insomne y nunca descansa, los redactores de esa declaración, como pidiendo disculpas, señalaron lo siguiente:

[...] no deberíamos olvidar que al hablar de Europa no solo deberíamos referirnos al euro, los bancos y la economía, ${ }^{2}$ sino que también debemos pensar en una Europa de conocimientos. Es deber nuestro el consolidar y desarrollar las dimensiones intelectuales, culturales, sociales y técnicas de nuestro continente. Estas han sido modeladas, en gran medida, por las universidades, que todavía desempeñan un papel imprescindible en su desarrollo. (Sorbonne Joint Declaration, 1998)

La gran aportación, como se indica en esta declaración, es la introducción, en el orden del saber, y en la lógica de las transmisiones, de un dispositivo bancario

1 Claude Allègre (Francia), Jürgen Ruetggers (Alemania), Luigi Berlinger (Italia), Tessa Blackstone (Reino Unido).

2 Curiosamente, en los últimos tiempos, y en especial en mi país, a punto de caer en la más absoluta de las ruinas, ¡no se habla de otra cosa! 
de medida: el "crédito" (el denominado ECTS, abreviatura de European Credit Transfer System):

Gran parte de la originalidad y flexibilidad de este sistema se conseguirá mediante el sistema de créditos, como en el sistema ECTS, (Sistema Europeo de Transferencia de Créditos) y semestres. Esto permitirá la convalidación de los créditos obtenidos para aquellos que elijan una educación inicial o continua en alguna de las universidades europeas y, asimismo, tengan intención de obtener una titulación. De hecho, los estudiantes deberían ser capaces de acceder al mundo académico en cualquier momento de su vida profesional y desde diversos campos. (Sorbonne Joint Declaration, 1998)

Lo que, a partir de esta unidad bancaria de medida, define el compromiso docente de profesores y discente de los estudiantes, es un número, una cantidad de horas dedicadas al estudio para lograr las competencias, habilidades y destrezas asignadas a cada disciplina. Porque lo importante es lograr que los estudiantes se preparen como "profesionales" competentes para un mercado en constante cambio y dinamismo. La definición de estas competencias derivan, no de la lógica de la propia disciplina, ni del sentido que los profesores, como investigadores o estudiosos de un campo de saber, estiman como las más adecuadas, sino de los denominados "empleadores", que son los que supuestamente contratarán a los egresados de la universidad. Es el mercado el que define la competencia, es decir, el resultado de un curso de enseñanza-aprendizaje. De este modo, el resultado estimado de un acto educativo (la enseñanza) no es educación-formación, sino, más exactamente, la capacidad para realizar técnicamente algo en un entorno profesional.

Pero al proceder de este modo algo pasa. Lo que ha ocurrido no es simplemente que una reforma universitaria haya tenido lugar o se haya decidido y puesto en práctica - una de tantas reformas-, es decir, que hayamos asistido, sin más, a una nueva reforma de los estudios universitarios cuyo propósito, supuestamente, es la calidad en la formación de nuestros universitarios (docentes y estudiantes) dentro de un espacio europeo común; lo que ha pasado es que al introducir como unidad de medida un concepto como el de "crédito" se han tornado equivalentes dominios que antes no parecían serlo de ningún modo, como no lo son la arqueología maya y la biología o la antropología cultural y la teoría del flogisto. Esta equivalencia de dominios disciplinares viene del hecho de que todas las disciplinas son susceptibles de traducirse en términos de número de créditos, o sea, en horas constantes y sonantes y, en definitiva, de dinero por unidad de tiempo.

Nace con ello el "conocimiento en general", un conocimiento sin distinción de contenidos, una modalidad de acceso al conocimiento que queda bien expresado en la llamada sociedad del conocimiento con sus eslóganes característicos: aprender a aprender y aprender a lo largo de toda la vida. Es una lógica extraña, pues solo una mano de obra, o una potencial mano de obra como la de nuestros alumnos universitarios, completamente descualificada necesita una permanente recualificación. Esos lemas de la sociedad del conocimiento y del aprendizaje, esa "educación permanente" 
aplicada a la universidad, ha hecho de ella, ya, un tipo de educación postsecundaria, una prolongación sine die de la enseñanza media, y, como institución de formación, algo profundamente carente de atractivo e interés.

Con independencia de que nos refiramos a estudios de corte humanístico o a disciplinas técnico-científicas, personalmente soy de la opinión de que la idea que prevalece hoy en las universidades es la de evitar las ideas, reducir lo singular y el papel de lo individual hasta su nulidad. Hoy se da por hecho que un profesor de universidad lo es con independencia de que, abandonando el estudio y la lectura paciente de los textos de su especialidad, dedique la mayor parte de su tiempo al desempeño de un cargo de gestión administrativa, sometiéndose al implacable rigor de todas las interminables encuestas de las agencias de evaluación de la calidad del profesorado, con el único propósito, en muchos casos, de obtener algunas prebendas en el fondo bastante humillantes.

Es absolutamente increíble que un alumno de doctorado de mi propia universidad, que realiza su tesis doctoral en mi propia facultad, obtenga en su curriculum vitae mayor valoración por el simple hecho de que su director de tesis se haya adscrito al llamado Programa docentia, que consiste básicamente en rellenar interminables cuestionarios de autoevaluación sobre la calidad en el desempeño de la propia actividad docente, o por parte de los alumnos, cuyos horarios están tan sobrecargados de tareas que apenas tienen tiempo, ni interés, en rellenar sus propias encuestas de evaluación de los profesores; o que obtengan puntuaciones favorables si sus directores poseen algún tipo de Proyecto de Innovación Educativa, los cuales se inscriben dentro del marco del Espacio Europeo de Educación Superior y que consisten, básicamente, en defender el uso de las tecnologías aplicadas al ámbito de la docencia universitaria. Si a cualquier cosa se le llama arte, podemos decir lo mismo en este campo: a cualquier cosa se le llama investigación. Entran ganas de vindicar las palabras estudio y enseñanza muy por encima de la palabra investigación, al menos cuando nos referimos a las ciencias humanas (Llovet, 2011, p. 166).

En mi opinión, estas políticas educativas universitarias, que restringen la educación a la enseñanza, o al aprender, en el modo en que acabo de señalar, no son meramente políticas dotadas de un cierto grado de normatividad o prescriptividad de un sector de realidad; se trata de politicas de la vida, políticas que aspiran a normalizar (gestionar, administrar, gobernar) la vida escolar en todos sus pormenores: constituyen la expresión de una fortísima biopolítica de la educación (Lewis, 2006, 2007, 2009). La reforma educativa universitaria a la que asistimos en Europa -aunque podría decirse que se trata de un asunto que trasciende el continente europeo-, está constituyendo, en este sentido, una auténtica corrupción pedagógica de los jóvenes estudiantes y alumnos. El Plan Bolonia tiene que ver con este propósito. Una corrupción y una corrosión del carácter, por decirlo con una expresión de Richard Sennett (2000), del ser mismo del estudiante o del alumno. Esta corrupción, tal y como yo la interpreto, tiene como efecto un proceso paulatino de minorización del estudiante, su extremada alumnización e infantilización. 
Este proceso tiene que ver con la importación que se ha realizado, al campo educativo, de una nueva cultura de la calidad y la excelencia (Jódar, 2007, p. 172). Con la introducción de una especie de "optimizacion sin fin", "flexible" y a "corto plazo" de las capacidades potenciales del alumno, el aprendizaje queda transmutado en un hacer donde el sentido y el valor de lo que se hace queda pospuesto, al mismo tiempo que se introduce una "maquinaria burocrática de meritocracia que crea una jaula de hierro para la capacidad", cuyas celdas, como jaulas o como cárceles, constituyen un confinamiento solitario (Sennett, 2006, p. 99). La vieja idea de un alumno que estudia y que aprende por el propio valor y disfrute del aprender queda, evidentemente, obsoleta en el nuevo contexto biopolítico.

Además, reformas como las mencionadas incorporan una extremada reglamentación del tiempo del aprender y del enseñar, suponen una clara disminución del espacio universitario, la desaparición de la autonomía académica frente al mercado, y la liquidación del Estado social. La reforma se ha presentado como una "revolución pedagógica", y en cierto sentido quizá lo es, porque ha horadado el sentido de la educación, y como un "cambio de paradigma"; pero, por lo que respecta a España al menos, de lo que se trata es de otra cosa: un zarpazo mortal a las estructuras de la enseñanza pública; y una erosión, sin paliativos, de una concepción pública del mundo.

\section{LA CORRUPCIÓN DE LA JUVENTUD. LA FUGA BLOQUEADA}

Es importante retener esta imagen: la educación tiene que ver con la salida hacia el exterior. Voy a ofrecer tres imágenes de esta salida; tres ficciones.

Pinocho, que es una marioneta, sale de casa, pero como se distrae no termina de llegar al colegio, el lugar destinado a educarse y a aprender; Peter Pan sale de la cuna para irse al país de Nunca Jamás, donde siempre se es un niño; Aquiles, escondido en el Gineceo, sale a hacer la Guerra de Troya, y de este modo abandona su anterior estado hedonista y placentero, donde no es ni verdadero hombre ni verdadera mujer.

Vamos a profundizar en esta última imagen. Ser adultos significa salir del Gineceo, como hace Aquiles, que es forzado, gracias a la astucia de Ulises, a asumir su responsabilidad en participación de la Guerra de Troya. Salir afuera, hacer la guerra, asumir la responsabilidad en la polis, esa sería, según esta imagen, ser adulto. Experimentarse como "fungible en el cotidiano cumplimiento del deber" (Gomá, 2007, p. 75), dice otro ensayista español. Ser adulto sería, según esta imagen, darse cuenta de que la vida no se regala, sino que la conquistamos dando algo a cambio: la vida hay que merecerla, dicen algunos. El escritor a quien cito, y con quien no puedo estar más en desacuerdo, dice: "La fecundidad se mide en la utilidad que una cosa reporta a los demás y es función, por tanto, de las preferencias y deseos de los otros miembros de la polis [...] Al especializarse, el sujeto profesionalizado adquiere una posición social y con ella una identidad" (idem, p. 114). 
La otra imagen de la salida es la que encarna una elección, por así decir, consistente en salir de la realidad hacia la fantasía, como le pasa a Peter Pan, cuyo único momento adulto es decidir no seguir creciendo más. Peter Pan es el niño eterno por excelencia. "Todos los niños, menos uno, crecen. Desde muy temprano saben que van a crecer” (Barry, 2005, p. 163). Así empieza el relato, primero obra de teatro, de James M. Barry. Todos los niños crecen, menos Peter Pan, que muy pronto supo que los dos años es el principio del fin. Él, como el resto de los niños del país de Nunca Jamás, son "niños alegres e inocentes". Pero también son otra cosa: son niños "sin corazón". Barry decía que la estatua de Peter Pan que descubrió en su honor en Kensigton Park no reflejaba al demonio que había en él. Cuando Peter Pan veía que los niños crecían, los eliminaba. ¿Quién es Peter Pan, entonces? No se sabe si es un niño o un joven. Su edad es indefinida, como la edad de Ernesto, en la novela de Marguerite Duras Lluvia de verano. Al nacer, los niños carecen de "conciencia moral". Pero su inocencia no significa que sean incapaces de hacer el mal, y tampoco significa que sean "buenos por naturaleza". Su inocencia no deja de tener esa perversidad propia de todo lo que es pura naturaleza, o mejor dicho, esa crueldad que tiene lo real. Son lo que son, pero no tienen conciencia de su propia existencia. Están más allá, o quizá más acá, de toda culpa.

Pero Peter Pan ha venido hasta nosotros como una idealización de la infancia, y el mito que lo funda nos conduce hasta el dios Pan, que en griego significa "todo". Pan, hijo de Hermes y de una ninfa que lo abandona nada más nacer, es el dios de los rebaños y de los pastores, y sigue con la flauta que toca al dios Dionisos. Es el dios de la fertilidad y de la sexualidad desenfrenada masculina. Persigue a las ninfas -que son las que secuestran a los niños y a los jóvenes- $\mathrm{y}$ vive en las selvas y en los bosques. Pan representa la "naturaleza salvaje" y se le atribuye la facultad de generar un miedo enloquecedor, es decir, de generar pánico. Peter Pan atesora este mito del dios Pan. En su vocación de totalidad, no distingue entre realidad y fantasía: "La diferencia entre Peter y el resto de los niños en una situación así (cuando jugaban) consistía en que ellos sabían que era pura ficción, mientras que, para él, la ficción y la verdad era exactamente lo mismo" (Barry, 2005, p. 275).Peter anhela ser siempre niño, permanecer en un estado de pura fantasía. Para sortear lo real, se inventa otra realidad ficticia. Peter representa el alma selvática del hombre, un cierto estado de naturaleza salvaje donde el bien y el mal no se pueden distinguir y donde determinadas distinciones conceptuales no son necesarias para vivir la existencia. Aquí no entra Rousseau todavía. Tiene, pues, una naturaleza en parte demoníaca, que espanta a la señora Darling, la madre de Wendy. Por eso, cada noche, puede verse a la madre de Wendy ordenando el mapa de las mentes de sus hijos. "La señora Darling oyó hablar de Peter por primera vez cuando estaba poniendo un poco de orden en las mentes de sus hijos" (idem, p. 171).

Acaso no sea otra cosa lo que tratamos de hacer en nuestras escuelas y en nuestras casas cuando decimos que educamos a los niños: poner un poco de orden en sus cabezas. Ese orden que les procuramos también es una forma que les imponemos y una cierta deformación inevitable. Siempre que damos una forma al 
mismo tiempo deformamos una forma que era originaria como promesa de forma. En eso tal vez consiste la pedagogía, como saber disciplinado y seguro de sí mismo.

Algunos han creído ver en Peter Pan todo esto y más. Un símbolo del tipo de infantilismo propagado en nuestras modernas sociedades. Es una especie de obstinación; querer a toda costa seguir siendo un niño; y pretender que despedir la infancia es traicionarla, en vez de celebrarla en grado sumo. ¿Acaso después de un recorrido educativo no hay que aprender a concluir, aprender a despedirse celebrando la potencia de vida y aprendizaje contenidos en la infancia? Nuestra sociedad del conocimiento, o del aprendizaje, como se la denomina es, en este sentido, una suerte de proceso que, alumnizando al aprendiz, lo convierte también en un aprendiz eterno: un aprendiz nunca del todo emancipado, un aprendiz que no se acaba soltar de la mano de sus educadores.

Si Peter Pan es la historia de un niño que se niega a crecer y a hacerse mayor de edad -podríamos decir: un niño que se niega a ir al colegio-, la historia de Pinocho es el relato de un "muñeco que aprende a portarse bien" (Pardo, 2010b, p. 41): acudir responsablemente al colegio sin distraerse por el camino, aprender a distinguir entre el bien y el mal, aprender a escuchar su conciencia moral, etc. Se trata de la historia de una marioneta que, para dejar de serlo -es decir, para dejar de ser manipulada por otros-, ha de aprender a ser persona, porque las personas tienen conciencia moral y eso, supuestamente, les hace capaces de dirigirse a sí mismos.

La historia de Pinocho, enredado en múltiples distracciones y pruebas, es un símbolo del niño-marioneta que en las sociedades modernas son objeto de una profanación sistemática "por parte de de pedagogos, psicólogos, médicos, etc., que usurpan la mítica propiedad de los padres” (Pardo, 2010b, p. 45). La historia de Collodi nos habla de una vida en el interior de una ballena, o mejor dicho de un tiburón; porque Pinocho tendrá que pasar por esa prueba final -hundirse en el vientre oscuro del tiburón-ballena- y rescatar a su padre para obtener el preciado don de una vida real de niño. Pinocho entra en el vientre oscuro y terrible del tiburón pero aún no sabe que su padre está también allí; luego sabrá. Ha aprendido. Entre ese no saber y el saber ulterior, Pinocho está perdido, desorientado. No sabe qué hacer. No tener un "quehacer" (por ejemplo un trabajo), es lo que nos distrae y desorienta. Después sabrá lo que tiene que hacer; hacer algo por el otro ("el otro" ya no es el lugar de donde proviene el infierno, como en la obra de teatro de Sartre): salvar a su padre, salir afuera, a la luz; es la prueba final; al ver la luz se ha ganado ser un niño. Ahora sí que puede ir, sin más distracciones, al colegio (Auster, 1997, p. 232-233).

Estas diferentes imágenes sugieren salidas hacia el exterior muy diferentes: hacia el mundo de los hombres que hacen la guerra; hacia el mundo de la fantasía, donde la guerra la hacen niños eternos contra sus correspondientes Garfios; hacia el vientre del tiburón-ballena, donde Pinocho tendrá que hacer algo por su padre, Gepetto, para obtener el preciado don de convertirse en un niño real. La escuela atraviesa, de algún modo, estas imágenes tan distintas entre sí: la guerra como una escuela que nos enseña lo que solo los adultos deben aprender (Aquiles); el país de Nunca Jamás, como escuela de fantasía donde uno hace siempre lo que quiere 
y sin límites, porque allí la realidad no es un límite de nada (Peter Pan); el mundo como lugar de tentación y de prueba, como una especie de escuela de la vida o como una escuela de formación de la conciencia moral (Pinocho). Estoy planteando la idea de la educación como salida hacia un cierto exterior y, al mismo tiempo, las diferentes formas de bloquearse o de desviarse, incluso de corromperse. He hablado, pues, de la educación como de una fuga bloqueada; un punto ciego. Y he introducido en mi argumento cierta idea de una posible corrupción de los jóvenes, como algo pedagógicamente viable, que sobrevuela en estas imágenes.

La corrupción de la juventud tiene su historia, y enuncia sus propios gestos. El filósofo Sócrates fue condenado a muerte por haber cometido, supuestamente, un doble crimen: no creer en los dioses de la ciudad y corromper a los jóvenes. La acusación de Meleto tiene que ver con un crimen religioso-moral, en vez de un crimen jurídico o político; un crimen de impiedad, porque la piedad, en el mundo griego, es lo que les debemos a los desiguales, sea por superioridad (los dioses) sea por inferioridad (los no-ciudadanos: las mujeres, los esclavos, por ejemplo). Ahora la corrupción de los niños y de los adolescentes se hace por motivos pedagógicos. A los niños hay que escolarizarlos para que aprendan qué es lo real y así sepan diferenciar entre realidad y fantasía. Y a los adolescentes, para los que "todo es falso", hay que re-escolarizarlos para que entren en razón y abandonen su injustificada rebeldía.

Al hablar de corrupción de la juventud uno piensa de inmediato en prácticas de pedofilia; pero yo no me voy a referir a eso. Sabemos que, así como la filosofía es la única disciplina que lleva en su denominación un sentimiento -philía-, la pedagogía es aquella disciplina que incorpora en su nombre el acompañamiento de los niños, o sea, el amor, el cuidado y el trato con los niños y con la infancia. Pero hemos corrompido ese nombre: hemos pasado de una paedophilia (de un amor a los niños o a los jóvenes, a quienes ayudamos a crecer) a un pedofilia, cierto amor corrupto, y corrompido, por ellos (Leclerc, 2010). La corrupción de la juventud, en los términos de una corrupción pedagógica, sugiere entonces el proceso consistente en minorizar al aprendiz: impedirle salir al mundo, romper los lazos y las ataduras, es decir, impedir que se emancipe.

La educación, como salida de una minoría de edad, consiste en una salida, pero no como la que hace Aquiles. No se trata simplemente de saber trabajar e incorporarse al mercado - que es como ir a una guerra, donde las personas se torturan entre sí, como en el infierno de Sartre-, ni desempeñar sin más un puesto laboral, o reunir en uno las competencias necesarias para la realización de una profesión. Significa aprender a in-corporarse al mundo (hacerse cuerpo con el mundo), que es público, en vez de permanecer eternamente bajo tutela: de nuestros padres, de nuestros profesores, de nuestros empleadores, de nuestros políticos. Y como decía al final de su ensayo "The crisis in education", Hannah Arendt (1996, p. 208):

la educación es el punto en que decidimos si amamos al mundo lo bastante como para asumir una responsabilidad por él y así salvarlo de la ruina que, de no ser por la renovación, de no ser por la llegada de los nuevos y los jóvenes, 
sería inevitable. También mediante la educación decidimos si amamos a nuestros hijos lo bastante como para no arrojarlos de nuestro mundo y librarlos a sus propios recursos, sin quitarles de las manos la oportunidad de emprender algo nuevo, algo que nosotros no imaginamos, lo bastante como para prepararlos con tiempo para la tarea de renovar un mundo común.

Ser adulto es, por último, reconocer el carácter ficticio de la narración en la que estamos -sea familiar, comunitaria o profesional-, dejar de confundir la realidad con la ficción (como suelen confundir siempre los niños), o dejar de decir que toda realidad es falsa (como suelen decir los adolescentes), y dejar de decir que el trabajo hace al hombre, porque la experiencia moderna muestra que el trabajo deshace algunas cosas en cada trabajador. Distinguir, pues, entre lo que tiene que ver con la verdad y la falsedad (una distinción que tiene que ver con lo público) y lo que tiene que ver con la ficción (algo que tiene que ver con lo comunitario o lo profesional).

Esta es la función de esa institución llamada escuela, entendida esta palabra en un sentido muy amplio: hacer de los hijos adultos responsables y mayores de edad, o sea, individuos. Una vez que esto ocurre, sin embargo, comienzan los verdaderos problemas para la comunidad humana, en un sentido, digamos, constructivo: pues la escuela, que procura que los niños devengan individuos, los devuelve a la sociedad emancipados, o supuestamente tales, de modo que, al ser capaces de pensar y actuar por sí mismos, puedan poner en cuestión el mundo y el espacio público -o para que, incluso, se vuelvan contra sus propios padres- denunciando sus abusos despóticos. Digamos que, al salir de la escuela, los niños se dan cuenta de que la narración o la ficción de la familia es una de tantas, pero no la única; que hay otras narraciones posibles, y que conviene confrontarlas entre sí. Porque es por esta vía por la que formamos nuestra capacidad de juzgar. La escuela, pues, les devuelve a la sociedad, eso es de lo que se trata, con capacidad de juicio, que según Kant es la característica de un ciudadano libre y educado, adulto.

Ahora bien, la escuela, y esa otra clase de escuela que es la universidad, hace con los jóvenes otra cosa: quiere convertirles en individuos competentes profesionalmente, capaces de trabajar con eficacia, es decir: trabajadores solventes. Y esta es otra clase de amenaza para la comunidad humana: la que proviene del trabajo. Y el trabajo amenaza, desde el espacio anónimo de la fábrica, a la comunidad al (co) romper los vínculos emocionales y familiares. El trabajo nos arranca de la comunidad natal, de sus lazos afectivos, de las lealtades familiares e incluso de las convicciones personales, arrojándonos a la intemperie. Nos hace salir afuera de otro modo.

Tenemos, por tanto, que la escuela tiene como función que salgamos afuera (al mundo) y que salgamos a esa parte del mundo que es el centro de trabajo. Hay educación porque, primero, hemos nacido - es la natalidad la que justifica que exista educación-y, segundo, porque hay mundo, porque hay un afuera y la posibilidad de un viaje y de una exposición. Pero lo que las reformas educativas de la universidad están poniendo en evidencia es otra cosa: que el interés por la educación (de los 
jóvenes) no es ahora enseñar cómo es el mundo y que se encaminen hacia él -para que allí encuentren el modo de elaborar su propio arte de vivir-, sino que salgan a una diminuta parte del mundo que es el mercado (como si mercado y mundo coincidiesen), que se encaminen, bien pertrechados de competencias, a la fábrica o al puesto de trabajo, aunque no sepan nada del mundo. Que se ganen la vida, que aprendan a mantenerla, en vez de aprender a vivirla. Así, no es extraño que por las escuelas y las universidades deambule un tipo de "estudiante formal" que es un producto acabado de un proceso de fabricación, y que solo escolarmente, puede subsistir (dentro de la escuela o del centro de trabajo) aunque resulte totalmente inoperante (e incompetente) dentro del mundo. Del mismo modo -hay un tipo de sofista, cierta clase, en definitiva, de pedagogo- cuya ocupación consiste en impedir que los niños y los estudiantes salgan del colegio, sujetos que aspiran a ejercer, como en cierto nodo el preceptor de Emilio, en la novela de Rousseau, una tutela o vigilancia pedagógica perpetua del otro, que tendrá que aprender a aprender eternamente.

El panorama actual del mundo escolar, y en especial del universitario, ha cambiado de tal modo que ya no es fácil pensar la transmisión de los saberes y las disciplinas en los términos que sugieren algunas de mis reflexiones anteriores. No se trata de hacer de ninguna propuesta un modelo a aplicar linealmente, sino de servirnos de sus intuiciones más valiosas para pensar una pedagogía de la transmisión de otro modo.

En este sentido, ya sé que no digo nada nuevo si afirmo que el modelo universitario vigente responde, en esencia, a la estructura misma de lo que se ha dado en llamar "sociedad del conocimiento", uno de cuyos defensores es, como se sabe, Anthony Giddens -y es sintomático al respecto que el organismo de su país encargado de gestionar y administrar la instrucción pública pasase de denominarse "Ministerio de Educación y Ciencia" a "Ministerio de Educación y habilidades (skills)"- que en un artículo del año 2006 decía: "En las actuales economías avanzadas, más del $80 \%$ de la mano de obra trabaja en los sectores de producción de conocimientos" (Giddens, 2006).

La cuestión a destacar aquí no es si el porcentaje más elevado de los empleados actualmente activos en nuestras sociedades son doctores, licenciados o titulados superiores -que en su mayoría seguramente no lo son-, sino que tales figuras, como otras no-universitarias, gracias a las artes de la sociedad del conocimiento se han igualado a través de uno de los eslóganes centrales de este modelo: la lifelong education. $Y$ esto es algo bien expresivo, en el fondo; pues, como ya dijimos, solamente una mano de obra perfectamente descualificada necesita una permanente recualificación. Esa es la contradicción.

También sé que una cosa es lo que señalen en términos de imperativo jurídico las normativas legales que regulan los nuevos títulos universitarios y otra bien diferente lo que se hace en el espacio y tiempo real y vital de un aula universitaria. Los buenos y malos profesores del antiguo modelo universitario seguirán siendo los mismos -buenos o malos, respectivamente- en el nuevo. Y, sin embargo, constatar esto -saber que, en el fondo, quien desee lograr ser el buen profesor al que aspira 
encontrará en el nuevo modelo oportunidades para lograrlo- no es suficiente para permanecer en silencio al respecto de algunas cosas; como cuando la ministra del anterior gobierno español, Cristina Garmendía, afirmaba que las humanidades tenían que implicarse mucho más de lo que están en el campo científico y tecnológico, lo que implicaba un cambio de actitud por parte de los humanistas. En mi país, con la reforma del Plan Bolonia han tenido que cerrar sus puertas muchos títulos de estudios humanísticos, y los que se han mantenido -como algunos estudios dedicados a las filologías, se han transformado en escuelas de idiomas. No hay que tener mucha imaginación para suponer lo que Nietzsche diría de esto.

Las palabras de la antigua ministra de educación esconden la pretensión de hacer pasar por investigación humanística lo que en realidad no es sino un trabajo técnico-instrumental que favorece los aspectos instrumentales de dichas investigaciones cuando son susceptibles de producir determinados rendimientos tecno-económicos, con la consecuencia de una devaluación de su elemento más sustantivo. De este modo, la investigación dejará de realizarse y de prosperar por su propio interés. El principio de rentabilidad y demanda social predomina aquí sobre cualquier otro y favorece, como de hecho se ha producido ya, la introducción en el orden del saber el aparato bancario de medida.

Como he sugerido, esta unidad de medida y de valor conferida a las "asignaturas" hace de ellas "conocimiento en general", sin mayor distinción de contenidos realmente relevantes. Así, como decía Claudio Magris (2008, p. 175) en un artículo publicado en el Corriere Della Sera el 22 de diciembre de 1999:

Hasta ahora se valoraba a un estudiante sobre la base de lo que demostraba saber, durante la prueba de un examen, acerca de la disciplina en cuestión y sobre la base de la inteligencia y la capacidad crítica con las que demostraba saber interpretar y reelaborar las nociones de las que se tratara. Era asunto suyo haber empleado uno o tres meses para entender un teorema o un acto del Hamlet. Ahora parece perfilarse la tendencia a cuantificar (en créditos) cualquier actividad de un estudiante, escolar y extraescolar: parece que no debiera quedar nada que fuera gratuito.

Todo ello parece la consecuencia de una tendencia que, en 1857, llevó a Marx a escribir lo siguiente:

La indiferencia respecto del trabajo determinado corresponde a una forma de sociedad en la cual los individuos pueden pasar con facilidad de un trabajo a otro y en la que el género determinado del trabajo es fortuito y, por consiguiente, les es indiferente. En este caso el trabajo se ha convertido no sólo categóricamente sino realmente, en un medio de producir riqueza en general, y ha dejado de confundirse con el individuo en un destino especial. (Marx, 2004, p. 187)

Esta sustitución del "trabajo particular" por el "trabajo en general” tiene resonancias más que evidentes en la sustitución de los saberes concretos en 
"conocimiento en general", una especie de "gelatina de conocimiento humano indiferenciado" que hace posible que un profesor de lo que hasta hace bien poco era un departamento universitario pueda dedicarse a impartir cualquier clase de "asignatura" de su departamento, porque lo único que cuenta es que cumpla con una dedicación docente equivalente a una serie de créditos. La docencia no se valora ya por la dedicación a un saber sobre el que hay que profundizar y extender, y que tiene su propio rigor y dificultad, sino que se mide en términos de una serie de créditos de docencia, importando bastante menos el contenido de la misma. La enseñanza es un tipo de actividad cuya temporalidad corresponde, por así decir, al tiempo de los hombres libres, una temporalidad que no es cronométrica, sino una que tiene que ver con la noción de un tiempo elástico y oportuno. Cabe preguntarse, entonces, “¿cómo podrían las enseñanzas de estos hombres ser comprimidas en los rígidos moldes de una 'clase', de un 'curso' o de un 'programa', siempre con sus límites explícitos y cronométricos y con su estructura clientelar” (Pardo, 2004, p. 115).

\section{A MODO DE CONCLUSIÓN}

Como he hablado de la salida, y de la educación como una especie de invitación a salir de casa, me parece bastante oportuno, para acabar, referirme a ese tipo de salida que, durante la década de los años sesenta, se repetía en cada casa, cuando los padres, un mañana cualquiera, encontraban una nota de un hijo o de una hija en la que les decía que se marchaban a vivir su vida.

En muchos casos, esas salidas tenían algún tipo de regreso, como en una Bildungsroman clásica, cuando la hija, después de haber experimentado parte del mundo, regresa para desempeñar su labor como un adulto que ha aprendido algo de la escuela de la vida. Pero muchos padres saben cómo terminan otras salidas de casa, "cuando el hijo retorna al hogar envuelto en un féretro militar o laboral o hecho pedazos y sin carácter".

Un día, sin embargo, es el hijo o la hija quien se encuentra una nota de sus padres, una carta que cuyo contenido podemos imaginar, y voy a citar un bellísimo texto de José Luis Pardo (2010c, p. 220), que entre otras cosas dice lo siguiente, tras el inevitable inicial comienzo: "querida hija":

Me pregunto, en fin, cómo podría mi experiencia -que, pese a todo, está llena de decepción y de amargura- servirte de algo a ti, que te diriges a un mundo convulsionado por la violencia más rastrera y a un mercado que exige a sus clientes una labilidad sobrehumana y condena a los inadaptados a la miseria material o moral, un mundo en el cual aquella gran maquinaria de la que se benefició mi generación se ha hecho calderilla en una infinitud de maquinitas clónicas que compiten por un premio insulso y soez, un mundo que, del mismo modo que exige a los edificios que se transformen hoy en centros comerciales, mañana en hoteles y pasado mañana en hospitales o complejos de oficinas, exige a los cuerpos y a las almas de las personas que se modulen y esculpan al son 
de las circunstancias más implacables. Pero, ¿Qué te diré cuando me preguntes si la ciudad está en armas, cuando quieras que te explique cómo sobrevivir en medio de una batalla, cómo protegerse contra la metralla o contra los inviernos? ¿Te diré que te diviertas? No sé si con esas palabras tan descaradas, pero aunque sea con otras, te diré seguramente que procures mirar en otra dirección, que no escuches a los padres que acusan a sus hijos ni a los hijos que acusan a sus padres de su infelicidad, ni mucho menos a los buhoneros que ofrecen recetas baratas y rápidas para enderezar a los hijos descarriados o para encarrilar a los padres nastuerzos, te diré que, cuando lluevan los obuses de hidrógeno o de estupidez, pues en verdad no sé cuáles son más letales ni si hay diferencia apreciable entre ambos, busques otros ojos en los cuales puedas percibir un destello de lucidez que te avise de que, aunque tu dolor sea tuyo y sólo tuyo, y aunque nadie pueda librarte de él (desconfía de todos los que te ofrezcan por él el oro y el moro), el dolor no lo es todo. Yo bien podría decir que mi vida no ha tenido ningún sentido ni ningún valor, que todo ha sido en vano, que todas las empresas en las que me he empeñado han fracasado, que mis congéneres han destruido cada una de mis esperanzas y me han privado de toda confianza en mis semejantes; bien podría decirlo si no fuera porque, al menos una vez, he visto unos ojos en los que brillaba una verdad distinta de la masacre y de la mezquindad, y ese solo instante ha valido por toda mi vida y ha convertido en nada todos mis desengaños y decepciones, y me ha enseñado a reírme con desprecio del sacrificio, la lucha por la vida, el sagrado valor del trabajo y de la humillación o la exaltación de la guerra, y me ha recordado el significado de la felicidad. Esos ojos, querida, son los tuyos, que me encuentro ahora, cuando estoy de vuelta, y que me recuerdan qué era lo que yo misma buscaba el día que abandoné la casa de mis padres, esa casa que hoy he vuelto a encontrar en el fondo de tu mirada. Así que, si no te digo nada, al menos, cuando nos crucemos en el camino, tú en el de ida y yo en el de vuelta, si percibes en mis ojos un temblor insensato de felicidad y de esperanza, un imperdonable deseo de detener la Historia y de declarar condonadas todas las deudas y clausuradas todas las hazañas, no olvides que eres tú quien los ha iluminado con esa luz y búscala ahí fuera, porque si la encuentras podrás fulminar con ella a quienes quieren hacerte desdichada. Es algo interior y profundo que se nos ha negado siempre, sistemáticamente, durante demasiados años.

\section{REFERENCIAS}

Arendt, Hannah. Entre el pasado y el futuro. Barcelona: Península, 1996.

Auster, Paul. La invención de la soledad. Barcelona: Anagrama, 1997.

BÁrcena, Fernando. The glow of fireflies. Philosophical essay for a recovery of the educational experience. Revista Innovación Educativa, México: IPN, v. 11, n. 55, p. 14-31, 2011. 
.El alma del lector. La educación como gesto literario. Bogotá, D.C., Colombia: Asolectura; Primero el lector, 2012a.

El aprendiz eterno. Filosofía, educación y el arte de vivir. Buenos Aires: Miño y Dávila, 2012b.

(2012c) Entre enfance et education. À propos d'une poétique du commencement. In: Kerlan, Alain; Loeffel, Laurence (Dirs.). Repenser l'enfance? París: Hermann. p. 299-314.

Barry, James M. Peter Pan. Madrid: Valdemar, 2005.

Biesta, Gert. Beyond learning. Democratic Education for a Human Future. Boulder, Co: Paradigm, 2006.

. Coming into the world, uniqueness, and the beautiful risk of education: an interview with Gert Biesta by Philip Winter. Studies in Philosophy and Education, Springer, v. 30, n. 5, p. 537-542, 2011. Disponible en: <http://www.springerlink.com/ content $/ 72831 \mathrm{~m} 0 \mathrm{u} 14112482 />$. Consultado en:

Collodi, Carlo. Las aventuras de Pinocho. Barcelona: Mondadori, 2010.

Deleuze, Gilles. Proust et les signes. París: PUF, 1964.

. Différence et repetition. París, PUF, 1968.

Giddens, Anthony. Mejorar las universidades europeas. El País, Prisa: Madrid, 10 abr. 2006.

Gomá, Javier. Aquiles en el Gineceo, o aprender a ser mortal. Valencia: Pre-Textos, 2007.

ЈАсотот, Joseph. Enseñanza universal. Lengua materna. Buenos Aires: Editorial Cactus, 2008.

JódAR, Francisco. Alteraciones pedagógicas. Educación y políticas de la experiencia. Barcelona: Laertes, 2007.

Leclerc, Anne. Padophilia, ou l'amour des enfants. París: Actes Sud, 2010.

Lewis, Tysson. The schooll as an exceptional space: rethinking education from perspective of the biopedagogical. Educational Theory, v. 56, n. 2, p. 159-176, 2006.

Biopolitical utopianism in educational theory. Educational Philosophy and Theory, v. 39, n. 7, 2007.

. Education and the immunization paradigm. Studies in Philosophy of Educcation, v. 28, p. 485-498, 2009.

Llovet, Jordi. Adiós a la universidad. El eclipse de las humanidades. Barcelona: Galaxia Gutenberg-Círculo de Lectores, 2011.

Magris, Claudio. Empresarialismo universal. In: La historia no ha terminado. Ética, política, laicidad. Barcelona: Anagrama, 2008. p. 175.

MARX, Karl. Introducción a la contribución de la crítica de la economía política. In: . Contribución a la crítica de la economía política. Granada: Comares, 2004. p. 187.

Masschelein, Jann. The discourse of learning society and the loss of chilhood. Journal of Philosophy of Education, v. 30, n. 1, p. 1-20, 2001. 
Pardo, José Luis. La intimidad. Valencia: Pre-Textos, 1996.

La regla del juego. Sobre la dificultad de aprender filosofía. Barcelona: Galaxia Gutenberg-Círculo de Lectores, 2004.

Entrevista a José Luis Pardo. In: Nunca fue tan hermosa la basura.

Barcelona: Galaxia Gutenberg-Círculo de Lectores, 2010a. ¿Qué quiere un niño. In: Nunca fue tan hermosa la basura. Barcelona: Galaxia Gutenberg-Círculo de Lectores, 2010b. p. 41-56.

Mother \& child reunion. In: Nunca fue tan hermosa la basura. Barcelona: Galaxia Gutenberg-Círculo de Lectores, 2020c. p. 203-220.

. El conocimiento líquido. En torno a la reformas de las universidades públicas. In: Nunca fue tan hermosa la basura. Barcelona: Galaxia Gutenberg-Círculo de Lectores, 2010d. p. 254-280.

Pennac, Daniel. Chagrin d'école. París: Gallimard, 2007.

RANCIÈRE, Jaques. El maestro ignorante. 1. ed. Barcelona: Laertes, 2003. . L'espectateur émancipé. París: La Fabrique Éditions, 2008.

2011. . El tiempo de la igualdad. Diálogos sobre política y estética. Barcelona: Herder,

Sennet, Jaques. La corrosión del carácter. Barcelona: Anagrama, 2000.

Sennet, Richard. La cultura del nuevo capitalismo. Barcelona: Anagrama, 2006.

SÁnchez Ferlosio, Rafael. La hija de la guerra y la madre de la patria. Barcelona: Destino, 2002.

Sorbonne Joint Declaration. 1998. Disponible en: <http://www.eees.es/pdf/ Sorbona_EN.pdf>. Consultado en:

\section{SOBRE EL AUTOR}

Fernando Bárcena es doctor en filosofía de la educación por la Universidad Complutense de Madrid (Espanha). Catedrático de la misma institución.

E-mail: fernando@edu.ucm.es

Recebido em agosto de 2012

Aprovado em outubro de 2012 